\title{
Measuring the Performance of Internal Audit Function in Saudi Listed Companies: An Empirical Study
}

\author{
Qasim Mohammad Zureigat ${ }^{1} \&$ Abdullah Al-Moshaigeh ${ }^{1}$ \\ ${ }^{1}$ College of Business and Economics, Qassim University, AlQassim, Saudi Arabia \\ Correspondence: Qasim Mohammad Zureigat, College of Business and Economics, Qassim University, \\ AlQassim, Saudi Arabia. Tel: 96-654-928-5785. E-mail: qasimmz@yahoo.com or $3903 @$ qu.edu.sa
}

Received: February 18, 2014

Accepted: May 12, 2014

Online Published: June 25, 2014

doi:10.5539/ibr.v7n7p72

URL: http://dx.doi.org/ibr.v7n7p72

\begin{abstract}
This study aims to explore whether Saudi listed companies are using performance measures to evaluate their internal audit function and, if they are, what performance measures they use to evaluate internal audit function and the identity of the important measures from the perspective of internal auditors. A questionnaire was designed and distributed to internal auditors in Saudi listed companies. The results show that Saudi listed companies are using both quantitative and quantitative performance measures to assess the internal audit function performance. Also, we find that internal auditors rank quantitative measures as important while qualitative measures are ranked as unimportant. The current study contributes to the existing literature by identifying key performance measures for the internal audit function in an emerging market, and provides valuable information about how to measure internal auditing performance. Also, this study is considered as the first one in Saudi market that identify such variable.
\end{abstract}

Keywords: internal audit, performance measures, Saudi listed companies

\section{Introduction}

Internal audit function objectives are now broader than ever; they have grown to cover risk management and corporate governance, in addition to the usual financial and operational aspects in the organizations (Spira and Page, 2003: Arena \& Azzone, 2009). This evolution of internal audit objectives and the related growth of its function require more effort in managing the internal auditing function. Bota and Palfi (2009) argue that despite the fact that internal audit is an integral part of the control framework of an organization; it is obvious that this function also must have its own controls to track whether its performance is consistent with its role and objectives.

Such controls over internal auditing must be linked to the organization objectives and strategy. Seminogovas and Rupsys (2006) presented the internal audit function as a mechanism that helps formulate organization strategy and achieve its goals. The internal audit function is assuming such an important role of organizational governance that it now stands as the most important mechanism for ensuring adequate and effective organizational governance (Ruud, 2003). Internal audit also can add value by helping organizations achieve economy, efficiency and effectiveness (Al-Twaijry, et, al., 2003) and can influence what is reported in a company's external financial statements (Prawitt, et.al., 2009). Haat et al. (2008) found that corporate governance factors have strong predictive powers of company performance and that one of these factors is internal auditing and that internal auditing's role in organizational goal achievement has been widely presented in the literature (Yee, et al., 2008; Mehrit, et al., 2010).

The importance of the internal auditing objectives and functions, especially with regards to controlling and managing the internal audit function emphases the need for a solid framework to assess and measure its performance in order to keep it working effectively. Rupsys and Boguslauskas (2007) found that the measurement of internal auditing performance is an important process not only from the perspective of internal auditors but also from that of its various stakeholders, and that though properly utilized performance measures is it able to communicate the value of the audit function to management (Vondra \& Schueler, 1993). Also, (IIA, 2009 , A) stated that the chief audit executive must develop and maintain a quality assurance and improvement program that covers all aspects of internal audit activity, and that this program should also assess the efficiency and effectiveness of internal audit activity. 
The above mentioned role for internal auditing and its importance makes it a sensitive function that should be measured in order to evaluate its effectiveness and its added value to the organization. Due to the lack of research in this area, we seek to identify key performance measures that can enhance the evaluation process. The research questions in this paper are as follows: (1) Do Saudi listed companies use performance measures to evaluate internal audit function performance? (2) If so, what are the performance measures used? (3) What are the most important measures that can be used to evaluate the effectiveness of the internal audit function? These questions are asked so that we can identify the key performance measures that can measure internal audit function performance, with respect to both quantitative and qualitative performance measures of internal auditing.

On one hand, this paper derives significance from the importance of the internal audit function and its sensitive role in the modern organizations; it's an integral part of corporate governance and risk management in addition to its important role in the financial statement reporting and operational perspectives. On the other hand, Saudi listed companies are regarded as important players in the Saudi economy which is considered the largest economy in the Middle East region. The characteristics of the Saudi economy, as an emerging economy in a developing country, contribute to the current study through exploring the reality of measuring internal audit performance in such an environment. Most of the previous studies have examined the internal audit function in developed countries, while developing countries received less attention Al-Twaijry, et al. (2004).

Therefore, it is very important to help Saudi listed companies that work in an emerging economy to address the key performance measures for the internal audit function. These measures will be a guide to achieve and sustain this strategic function's objectives and effectiveness especially when considering the Al-Twaijry, et al. (2004) study that found that the internal audit function in many Saudi companies lacked professionalism and independence from management (which adversely affected its work). The results of the current study will help Saudi listed companies to select the most relevant and best performance measures to evaluate the internal audit function.

Specifically, this paper aims to explore the reality of measuring internal audit performance in certain Saudi listed companies by studying whether Saudi listed companies are using performance measures to evaluate their internal audit function. If these companies are using performance measures, the performance measures used to evaluate internal audit function and the importance of measures from the perspective of internal auditors is identified. Moreover, it aims to study the importance of these measures by using quantitative and qualitative performance measures of internal auditing. Also, this study identifies key performance measures for the internal audit function to help Saudi listed companies to assess and evaluate the effectiveness of their internal audit departments.

\section{Literature Review}

Measuring internal audit function performance hasn't captured much attention from researchers; this area is still awaiting more efforts to construct a framework that enables management to assess and evaluate internal audit activities. Rupsys (2007) stated that measuring the performance of internal audit function is a quite complex and difficult task for practical implementation. Prior literature has attempted to highlight the mechanisms of assessing internal audit performance and the research on identifying factors affecting internal auditors work.

Schneider (2010) pointed out that audit committees are responsible for assessing internal auditing performance. That study analyzed these assessments and found some deficiencies in the audit committee's role in this area. The results indicated that having the audit committee review the internal audit function is not usually required by the committee's charter and is not sufficient to measure internal auditing performance. Zain, et al. (2006) examined the relation between characteristics of the audit committee, internal audit function and internal auditors' assessment of their contribution to financial statement audits in Malaysia. They found that internal auditors' contribution to the financial statements is affected by many factors related to the audit committee and internal audit function characteristics. Also, they found a positive relationship between extent of audit committee review of internal audit programs and the internal audit contribution to the financial statement audits. These results indicate that assessing the internal audit performance by audit committee reviews will increase internal audit effectiveness. Davies (2009) also confirms these results; he argues that audit committees have an important role to play in assessing the performance of the internal audit function and that, if this role is played, to the internal audit function will be more effective.

Arena and Azzone (2009) attempted to understand the organizational drivers of internal audit effectiveness. Their results indicated that internal audit effectiveness is influenced by many factors such as the characteristics of the internal audit team, the audit processes and activities, and the organizational links. They also provide examples of some indicators that affect internal audit effectiveness such as the ratio between the number of internal 
auditors and employees, audit committee involvement in the activities of the internal auditors and the adoption of control risk self-assessment techniques. Mihret and Yismaw (2007) identified factors impacting internal audit effectiveness in the Ethiopian public sector. The study found that internal audit effectiveness is strongly influenced by internal audit quality and management support, whereas organizational setting and auditee attributes do not have a strong impact on audit effectiveness.

Other literature on the area of evaluating internal auditing performance explored the evaluation of internal auditing by external auditors and their coordination. Al-Twaijry et al. (2004) examined the relationship between the internal and external audit functions in the Saudi Arabian corporate sector. Their results revealed that external auditors expressed concern about the independence, scope of work, and small size of many internal audit departments. External auditors suggested that the objectivity, competence and work experience of internal auditors were important factors affecting the decision to rely on the work of internal auditors. Desai, et al. (2009) developed an internal auditing assessment model that considers interrelationships among specific factors used by external auditors to evaluate the strength of the internal auditing function based on three factors: competence, work performance, and objectivity. The study also identified specific elements used in the current study to evaluate each factor. The study concluded that when three factors have a strong or a perfect relationship, the strength of the internal audit function remains high even if there is positive or negative evidence about one of the factors. Also, Desai and Desai (2010) assert that the model developed by Desai et al. (2009) is an important step towards developing a decision aid for external auditors for evaluating the internal audit function. They argue that the three factors of their model can be used to evaluate the internal audit function and must be considered together in order to determine whether the internal auditing function operates well. The results of a recent study by Anderson et al. (2012) reveal that the internal audit function size is inversely associated with the percentage of internal audit employees that are Certified Internal Auditors and the extent of assurance and compliance activities outsourced to outsiders. The role of these two factors decreases the amount of work performed by the internal auditors and is an indicator of performance.

The above mentioned studies involved studying and identifying factors that affect internal auditing function in order to improve the effectiveness and quality of internal audit function. They identified various factors or characteristics that can improve the performance of internal audit function. Although they provide a framework to establish performance measures for internal auditing function, only a few studies formulate an integral framework that can be used inside the organizations to measure internal auditing performance and to evaluate this activity. Bota and Palfi (2009) mentioned that the focus of the research in this area became increasingly important after the release of the new version of internal auditing standard 1300 issued by The Institute of Internal Auditors in 2008 and applicable with 2009.

Seminogovas and Rupsys (2006) produced a comprehensive model to measure internal audit performance using the balanced scorecard framework, taking into consideration the linkage between internal audit and mission, goals, and strategy of the organization. Their framework for measuring internal auditing performance consists of four perspective encompassing innovation, competence and capabilities; auditing process; audit clients; and value and status of internal audit. These four perspectives must include short and long term performance measures, internal and external performance measures, leading and lagging indicators, and objective and subjective measures. The study argues that such a model will enable the internal audit function to play a significant role in achieving the organizational goals and strategy.

Rupsys and Boguslauskas (2007) provided empirical evidence on measuring internal auditing performance. They argue for the need to measure internal auditing performance using nontraditional measures that expand the current focus on efficiency and effectiveness. Also, they addressed the lack of evidence for a strong and complete framework for measuring internal audit performance. Their results highlighted the importance of measuring internal audit performance and presented the Input, Process, and Output model as an effective mechanism to measure internal audit performance.

The study of the Austin Chapter Research Committee (2009) captured a snapshot of how internal audit practitioners use performance measures; the results showed that the use of performance measures is still not universal for the internal audit function. Also, the most commonly used performance measures are related to audit quality, while very few financial efficiency measures are being used and almost no impact measures are to be found. Moreover, small internal audit departments are less likely to use performance measures than are larger ones. The study provided numerous examples about different types of performance measures that can be used to measure internal audit performance.

Measuring internal audit performance is still not grounded in a strong framework or model; there is no evidence 
that measures proposed by prior research can deliver the expected added value for internal audit function, especially in the emerging economics. This is supported by the results of Bin Kasim and Hanafi (2012) which indicate that most of the existing instruments measuring internal audit quality suffer major weaknesses that limit their value.

\section{Hypotheses}

The first hypothesis of this study is explores the reality of using performance measures to measure internal audit function performance in the Saudi listed companies. Some studies, e.g., Austin (2009) found that almost 30\% of the respondents don't have an established performance measures in their organizations. Thus, the first hypothesis of this study of this study explores the reality of measuring internal audit performance in the Saudi context:

H1: Saudi listed companies don't use performance measures to evaluate their internal audit function performance.

The main purpose of the Bota and Palfi (2009) study was to identify the most significant types of methods used in determining the performance of internal auditors. The study presents quantitative and qualitative methods for measuring internal audit function performance. Also, it provides evidence on using measurement tools like the balanced scorecard. They conclude that the choice of method depends on the management's belief of what method will best reflect internal audit's relevancy and efficiency and especially the strategic role of the internal audit function.

While the first hypothesis identifies the reality of using performance measures in general, the second and third hypothesis identifies the reality of using performance measures with regard to both quantitative and qualitative measures. Bota and Palfi (2009) indicated that internal audit performance measures can be classified as quantitative and qualitative measures. The main difference between quantitative and qualitative performance measures is that quantitative measures focus on daily regular operations, where qualitative measures focus on the long term perspective with regards to the general quality issues. The following two hypotheses examine the use of qualitative and quantitative performance measures separately:

H2: Saudi listed companies don't use quantitative performance measures to evaluate their internal audit function performance.

H3: Saudi listed companies don't use qualitative performance measures to evaluate their internal audit function performance.

Although these three hypotheses examine whether Saudi listed companies are using performance measures in evaluating the internal audit function performance with respect to both quantitative and qualitative measures, we need to know the importance of the measures with respect to improving the quality of measuring the internal audit function performance. Hypothesis four and five are formulated to produce this evidence:

H4: Quantitative performance measures are not important in evaluating the internal audit function performance in Saudi listed companies.

H5: Qualitative performance measures are not important in evaluating the internal audit function performance in Saudi listed companies.

This study extends the contributions of the literature by exploring the reality of measuring internal audit performance in Saudi listed companies; it also investigates the importance of measures that can be used in this sector to evaluate internal audit performance. By investigating the present situation of measuring the performance of internal audit function, the current study provides valuable data for both regulators and top management in Saudi organizations. Also, the results of the current study will be very useful in identifying important measures that can be used to assess the performance of the internal audit function, which in turn provides a mechanism by which the quality of this critical function can be improved.

\section{Sample}

Measuring internal audit performance in the Saudi listed companies will be explored through this study, the process of measuring internal audit performance is not assigned for one person or one party in the firm. Schneider (2010) stated that evaluation of internal audit function is one of the audit committee responsibilities and can be done using both external or internal sources. Desai and Desai (2010) and Krishnamoorthy (2002) focused their papers on external auditor assessment of the internal audit performance. Also, IIA (2009, A) pointed to standard number 1300 that the chief audit executive must develop and maintain a quality assurance and improvement program which includes an evaluation of internal audit performance. The number of parties whose are responsible for measuring internal audit performance leads us to focus on the internal auditors as a 
source of the data rather than looking to others as the source of the data questionnaire. Therefore, the study sample consists of all chief internal auditors and internal auditors in Saudi listed companies (the total number of those auditors is not available in the published data). Therefore, the questionnaire was distributed to the internal auditing department in each listed company, and they were asked to allow each working auditor to answer it. In Saudi Arabia, 160 companies are listed in on the Saudi Stock Exchange (TADAWUL, 2013).

In this case, the results of the current study demonstrate the view point of the internal auditors which, in turn, resulted in exploring the measures used to evaluate the performance of the internal audit function. The internal auditors were to answer the questions based on their belief as to how their work is evaluated.

\section{Data Collection}

In order to collect the data needed for this study, a questionnaire was designed to contain questions about the internal auditing performance measures used in the Saudi listed companies. Moreover, it asks the study participants about the use of internal audit function performance measures and the most important measures that Saudi listed companies use to evaluate their internal audit function. This information is captured through the use of closed ended questions. The questionnaire is divided into two parts, the first questions ask if the companies are using defined measures; the answers for the questions in this parts were 1and zero ( 1 if the company is using the defined performance measure and zero otherwise). The second part contains questions about the importance of these measures from the view point of the internal auditors in the Saudi listed companies.

A five-point Likert scale (where $1=$ least important and $5=$ most important) was used to help determine the importance of each measure listed in the second part of the questionnaire. The researchers rely on literature and professional publications in this field to identify the common preferred measures in evaluating internal auditing performance with respect to both quantitative and qualitative measures, (Bota and Palfi, 2009; Austin Chapter Research Committee, 2009; IIA, 2009, B). Also, through the two parts, the researchers used both quantitative and qualitative measures to explain the current status in the Saudi listed companies.

The questionnaire was distributed to all listed companies that agreed to participate in this study (98 companies). Most of companies that refused to complete the questionnaire used confidentiality as the reason for not participating. The researchers collected 134 questionnaires. Most of companies completed only one questionnaire (by the internal auditing manager), while a few of them completed more than one.

\section{Analysis and Results}

Questionnaire Based on the data collected from 134 questionnaires, the descriptive statistics that are presented in table 1 show that Saudi listed companies are using defined performance measures. In general, the mean of responses for questions that ask about using internal audit performance measures is 0.49 with a standard deviation 0.17; this indicates that Saudi listed companies are using performance measures to assess the performance of the internal audit function. At the same time, table 1 illustrates that the mean of responses for questions that ask about the quantitative performance measures is higher (reach 0.57 with the same standard deviation 0.17), while the mean of the responses for questions that ask about using qualitative performance measures is lower than the previous two means ( 0.37 with higher standard deviation 0.26 ).

These results for the descriptive statistics indicate that Saudi listed companies are using performance measures to evaluate the performance of its internal audit function. At the same time, it shows that quantitative performance measures are used more often than are qualitative performance measures.

Table 1. Descriptive statistics

\begin{tabular}{lcccc}
\hline & Minimum & Maximum & Mean & Std. Deviation \\
\hline Use all measures & 0.18 & 0.71 & 0.49 & 0.17 \\
Use quantitative measures & 0.24 & 0.71 & 0.57 & 0.17 \\
Use qualitative measures & 0.08 & 0.69 & 0.37 & 0.26 \\
Importance of all measures & 2.47 & 3.82 & 3.35 & 0.51 \\
Importance of quantitative measures. & 2.86 & 3.81 & 3.48 & 0.37 \\
Importance of qualitative measures. & 1.15 & 3.85 & 3.1 & 1 \\
\hline
\end{tabular}

The above mentioned results for descriptive statistics leads to a critical question: What are the most often used performance measures in Saudi listed companies? Table 2 presents frequency statistics about the use of the 
defined measures. It is clear that many quantitative performance measures are used across all respondents and gives an indication of the measures they are using. While qualitative performance measures are not used as often as are quantitative ones, some of these measures are not used at all in the Saudi context, especially external and peer reviewing tests which are considered important mechanisms to assess professionals. These frequencies provide a deep understanding about the reality of performance measures used in Saudi listed companies.

Table 2. Frequency statistics for used measures in Saudi listed companies

\begin{tabular}{|c|c|c|c|c|}
\hline \multirow{2}{*}{$\begin{array}{ll} & \text { Measure } \\
\text { Quantitative Measures } & \end{array}$} & \multicolumn{2}{|c|}{ Used } & \multicolumn{2}{|c|}{ Not Used } \\
\hline & Frequency & Percent $\%$ & Frequency & Percent $\%$ \\
\hline Percent of completion against audit plan & 134 & 100 & 0 & 0 \\
\hline Time required for issuing audit report & 109 & 81.3 & 25 & 18.7 \\
\hline Time required for solving problems encountered during audit & 53 & 39.6 & 81 & 60.4 \\
\hline Time required to implement audit tasks & 134 & 100 & & \\
\hline Number of violations that have been solved by passage of time & 27 & 20.1 & 107 & 79.9 \\
\hline Number of violations solved in excess of planned time & 27 & 20.1 & 107 & 79.9 \\
\hline Number of violations that have not been solved & 53 & 39.6 & 81 & 60.4 \\
\hline Number of employees in the IA department & 109 & 81.3 & 25 & 18.7 \\
\hline Number of requests by management & 59.7 & 40.3 & 80 & 59.7 \\
\hline Number of meeting with the CEO & 0 & 0 & 134 & 100 \\
\hline Planned vs. actual time for audit task & 134 & 100 & 0 & 0 \\
\hline Number of implemented recommendations & 27 & 20.1 & 107 & 79.9 \\
\hline Number of consultancy services provided by IA department & 134 & 100 & 0 & 0 \\
\hline Number of improvement recommendations provided by IA Department & 134 & 100 & 0 & 0 \\
\hline Experience of internal auditing team by years & 55 & 41 & 79 & 59 \\
\hline Number of training hours & 109 & 81.3 & 25 & 18.7 \\
\hline Yearly turnover rate for internal auditing team & 82 & 61.2 & 52 & 38.8 \\
\hline Planned vs. actual financial and human resources & 28 & 20.9 & 106 & 79.1 \\
\hline Number of professional certificates & 26 & 19.4 & 108 & 80.6 \\
\hline Qualitative Measures & Frequency & Percent $\%$ & Frequency & Percent $\%$ \\
\hline Results of peer review tests & 0 & 0 & 134 & 100 \\
\hline Research and development activities & 54 & 40.3 & 80 & 59.7 \\
\hline Questions after performing audit task & 28 & 20.9 & 106 & 79.1 \\
\hline Interviews after performing audit task & 82 & 61.2 & 52 & 38.8 \\
\hline Questions about the value added by audit function & 54 & 40.3 & 80 & 59.7 \\
\hline Auditees questions & 28 & 20.9 & 106 & 79.1 \\
\hline Management questions about audit function & 54 & 40.3 & 80 & 59.7 \\
\hline Achievement of quality targets & 51 & 38.1 & 83 & 61.9 \\
\hline External review for IA & 0 & 0 & 134 & 100 \\
\hline Audit committee questions & 82 & 61.2 & 52 & 38.8 \\
\hline Stakeholders questions & 26 & 19.4 & 108 & \\
\hline Stakeholders feedback & 54 & 40.3 & 80 & 59.7 \\
\hline Reliance on internal auditors & 109 & 81.3 & 25 & 18.7 \\
\hline
\end{tabular}

These statistics indicate that Saudi listed companies use performance measures to assess the performance of internal audit function. The importance of these measures is described in table 3 which provides insight as to how internal auditors use the measures. 
Table 3. Descriptive statistics

\begin{tabular}{lcccc}
\hline & Minimum & Maximum & Mean & Std. Deviation \\
\hline Use all measures & 0.18 & 0.71 & 0.49 & 0.17 \\
Use quantitative measures & 0.24 & 0.71 & 0.57 & 0.17 \\
Use qualitative measures & 0.08 & 0.69 & 0.37 & 0.26 \\
Importance of all measures & 2.47 & 3.82 & 3.35 & 0.51 \\
Importance of quantitative measures. & 2.86 & 3.81 & 3.48 & 0.37 \\
Importance of qualitative measures. & 1.15 & 3.85 & 3.1 & 1 \\
\hline
\end{tabular}

In table 3, we note that internal auditors perceive that use of the defined performance measures is important. Their answers were collected based on Likert scale (where $1=$ least important and $5=$ most important). The mean for their answers to all measures is 3.35 (above the test value 3 ) with a smooth standard deviation 0.51 . But after dividing these measures into quantitative and qualitative, we see that the mean for the answers involving quantitative measures is higher than the mean for qualitative answers (3.48 and 3.10, respectively), with standard deviations ( 0.37 and 0.99 , respectively), which indicate that internal auditors in Saudi listed companies consider quantitative performance measures more important than qualitative measures.

To have a deeper clarification, additional descriptive statistics for the importance of the defined performance measures are presented in table 4 . The mean number indicates the level of importance of each measure. It is clear that internal auditors agree that percent of completion against audit plan is the most important quantitative measure while number of meetings with the CEO is the lowest important one. At the same time, respondents indicate that stakeholders' feedback is the most important qualitative measure, while questions asked after performing audit tasks is the least important one. Table 4 presents data on what measures internal auditors think companies will use to assess their performance. These data can be used by organizations to build their assessment systems.

Table 4. Descriptive statistics for the importance of performance measures

\begin{tabular}{lcc}
\hline \multicolumn{1}{c}{ Measure } & \multicolumn{2}{c}{ Impotency } \\
\hline Quantitative Measures & 5 & Std. Dev. \\
\hline Percent of completion against audit plan & 4.19 & 0 \\
Time required for issuing audit report & 2.78 & 1.47 \\
Time required for solving problems encountered during audit & 4.79 & 0.41 \\
Time required to implement audit tasks & 2.19 & 0.99 \\
Number of violations that have been solved by passage of time & 2.19 & 0.99 \\
Number of violations solved in excess of planned time & 2.78 & 1.47 \\
Number of violations that have not been solved & 4.59 & 0.49 \\
Number of employees in the IA department & 3.57 & 1.75 \\
Number of requests by management & 1.4 & 0.49 \\
Number of meeting with the CEO & 4.79 & 0.41 \\
Planned vs. actual time for audit task & 2.4 & 1.37 \\
Number of implemented recommendations & 4.79 & 0.41 \\
Number of consultancy services provided by IA department & 4.59 & 0.49 \\
Number of improvement recommendations provided by IA Department & 3.19 & 1.84 \\
Experience of internal auditing team by years & 4.19 & 1.17 \\
Number of training hours & 3.4 & 1.63 \\
Yearly turnover rate for internal auditing team & 2.44 & 1.37 \\
Planned vs. actual financial and human resources & 3.8 & 1.48 \\
Number of professional certificates & & \\
\hline
\end{tabular}




\begin{tabular}{lcc}
\hline Qualitative Measures & & \\
\hline Results of peer review tests & 2.58 & 1.02 \\
Research and development activities & 3.38 & 1.19 \\
Questions after performing audit task & 1.6 & 0.49 \\
Interviews after performing audit task & 1.81 & 1.19 \\
Questions about the value added by audit function & 3.4 & 1.21 \\
Auditees questions & 3.4 & 1.21 \\
Management questions about audit function & 2.19 & 1.15 \\
Achievement of quality targets & 2.81 & 1.49 \\
External review for IA & 3.58 & 1.36 \\
Audit committee questions & 3.38 & 1.36 \\
Stakeholders questions & 3.61 & 1.51 \\
Stakeholders feedback & 3.78 & 1.47 \\
Reliance on internal auditors & 3.79 & 0.98 \\
\hline
\end{tabular}

To examine the hypotheses, the one-sample $t$ test is used based on a specific test value for each hypothesis. The first hypothesis tests whether Saudi listed companies are using performance measures to assess the performance of internal audit function.

Table 4 presents the statistics for the one-sample t test used to test this hypothesis. Clearly, Saudi listed companies are using defined measures in assessing the performance of internal audit function; the t-value is 33.05 at 0.00 sig. level, which leads to the rejection of the first null hypothesis.

Table 5. One-sample test for using measures

\begin{tabular}{lcccc}
\hline & \multicolumn{3}{c}{ Test Value $=0$} \\
\cline { 2 - 5 } & $\mathrm{t}$ & $\mathrm{df}$ & Sig. (2-tailed) & Mean Difference \\
\hline Use all measures & 33.05 & 133 & 0 & 0.49 \\
Use quantitative measures & 38.47 & 133 & 0 & 0.57 \\
Use qualitative measures & 16.74 & 133 & 0 & 0.37 \\
\hline
\end{tabular}

At the same time, both hypothesis $\mathrm{H} 2$ and $\mathrm{H} 3$ are designed to investigate whether Saudi listed companies are using quantitative and qualitative performance measures.

Based on the results of the one-sample t-test presented in table 4, we reject both null hypotheses regarding quantitative and qualitative measures (the t-values are 38.47 and 16.34, respectively). These results indicate that Saudi listed companies are using both quantitative and qualitative measures, but quantitative ones are much more likely to be used.

Such results can be explained through the strength of accounting and auditing regulations in the Saudi context. Saudi accounting and auditing standards were classified as 19th out of 144 countries in the Global Competitiveness Report (2012-2013) issued by World Economic Forum (2013). Also, Saudi Arabia has more than one monitoring agency that supervises and controls listed companies (e.g., the Saudi Arabian Monetary Agency that supervises the Banking and Insurance sector; the Saudi Stock Exchange that monitors all Saudi listed companies; and ministry of commerce that supervise all Saudi companies). Also, Saudi economy gets rank 18th worldwide (World Economic Forum. 2013), which means higher competition and much transparency needs for Saudi companies. All of these factors can be considered as motivators to control a critical function as internal auditing in Saudi listed companies. At the same time, such results are in line with the findings of the Austin Chapter Research Committee (2009) which indicate that measuring internal audit performance is very important (but still without a comprehensive framework).

The use of performance measures to assess the performance of internal audit function that has been evidenced earlier does not fully meets the study objectives; both hypothesis H4 and H5 are designed to clarify which 
performance measures, quantitative or qualitative, are more important in the Saudi context.

Table 5 presents the results of a one-sample t-test that answers this question based on a test value that equals 3 . The results indicate that internal auditors in the Saudi listed companies agree on the importance of quantitative performance measures where the $t$ value is positive and equals 14.79 at zero significance Level. This leads us to reject the fourth null hypotheses. Whereas they don't seem to agree on the importance of the qualitative performance measures, the $\mathrm{t}$-value is a positive 1.21 but is not significant.

Table 6. One-sample test for the importance of measures

\begin{tabular}{lcccc}
\hline & \multicolumn{3}{c}{ Test Value $=3$} \\
\cline { 2 - 5 } & $\mathrm{t}$ & $\mathrm{df}$ & Sig. (2-tailed) & Mean Difference \\
\hline Importance of all measures & 7.87 & 133 & 0 & 0.35 \\
Importance of quantitative measures. & 14.8 & 133 & 0 & 0.48 \\
Importance of qualitative measures. & 1.21 & 133 & 0.23 & 0.1 \\
\hline
\end{tabular}

Such a result can be explained through the higher subjectivity of the evaluating person when using qualitative performance measures compared to the quantitative measures, especially when considering that this study is of an emerging market like the Saudi market. Also, the weakness in using peer review tests and external reviewers as shown in table 2 clarifies this result and supports the reasoning that internal auditors don't consider qualitative measures as important as quantitative ones due to the subjectivity of these matters. Also, these results are consistent with Bota and Palfi (2009) who explained the difference between quantitative and qualitative performance measures and how can they be used by organizations.

\section{Discussion and Conclusion}

The internal audit function is becoming more important due to its role in modern organizations as a strategic tool that is linked to the organizational objectives. This importance increases the need to have a solid framework to assess and measure its performance in order to maintain the effectiveness of the work that internal auditors perform. Previous literature hasn't adequately devoted enough attention to this area and this inadequacy reflects the need to explore how organizations are assessing the performance of the internal audit function. The current study aims to explore the performance measures that are used to evaluate the internal audit function in Saudi listed companies, and to identify the important measures with respect to both quantitative and qualitative performance measures. The current study contributes to the literature by exploring the reality of measuring internal audit performance and the importance of the internal audit function. Also, the results of the current study are very useful in addressing and identifying the important measures that can be used to assess the performance of the internal audit function especially in an emerging and fast growing economy like the Saudi Arabia market. A questionnaire was developed based on relevant literature and professional publications and distributed to internal auditors in Saudi listed companies. The results of the statistical analysis reveal that Saudi listed companies are using both quantitative and qualitative performance measures. Also, internal auditors are considering quantitative measures more important than qualitative measures. At the same time, we find that internal auditors agree that percent of completion against audit plan is the most important quantitative measure while number of meetings with the CEO is the least important one. At the same time, respondents believe that stakeholders' feedback is the most important qualitative measure, while s asking questions after performing audit tasks is the least important one. The results of the current study can be explained by reference to the large size of the Saudi market and its strong regulators, while at the same time, subjectivity in the qualitative performance measures may be the reason behind the internal auditors' lower opinion about the importance of these measures. An additional investigation on the factors that affect the performance of internal audit function, and how companies are implementing the performance measures is important, especially in emerging economies like Saudi.

\section{References}

Al-Twaijry, A. A. M., Brierley, J. A., \& Gwilliam, D. R. (2003). The Development of Internal Audit in Saudi Arabia: An Institutional Theory Perspective. Critical Perspectives on Accounting, 14(5), 507-531. http://dx.doi.org/10.1016/S1045-2354(02)00158-2

Al-Twaijry, A. A. M., Brierley, J. A., \& Gwilliam, D. R. (2004). An Examination of the Relationship Between 
Internal and External Audit in the Saudi Arabian Corporate Sector. Managerial Auditing Journal, 19(7), 929-944. http://dx.doi.org/10.1108/02686900410549448

Anderson, U. L., Christ, M. H., Johnstone, K. M., \& Rittenberg, L. E. (2012). A Post-SOX Examination of Factors Associated with the Size of Internal Audit Functions. Accounting Horizons, 26(2), 167-191. http://dx.doi.org/10.2308/acch-50115

Arena, M., \& Azzone, G. (2009). Identifying Organizational Drivers of Internal Audit Effectiveness. International Journal of Auditing, 13(1), 43-60. http://dx.doi.org/10.1111/j.1099-1123.2008.00392.x

Austin Chapter Research Committee. (2009). Performance Measures of Internal Functions: A Research Project. The Institute of Internal Auditors Research Foundation, Austin Chapter, USA.

Bin Kasim, M. A., \& Hanafi, S. R. B. (2012). Assessment of quality for internal audit functions: A quest for a valid and reliable instrument. African Journal of Business Management, 6(9), 3402-3412.

Bota, C., \& Palfi, C. (2009). Measuring and Assessment of Internal Auditor's Effectiveness. Annals of the University of Oradea, Economic Science Series, 18(3), 784-790.

Davies, M. (2009). Effective Working Relationships Between Audit Committees and Internal Audit-the Cornerstone of Corporate Governance in Local Authorities, a Welsh Perspective. Journal of Management and Governance, 13(1-2), 41-73. http://dx.doi.org/10.1007/s10997-008-9070-9

Desai, R., \& Desai, V. (2010). Towards a Decision Aid for External Audit Evaluation of the Internal Audit Function. Journal of Global Business Issues, 4(1), 69-72.

Desai, V., Roberts, R. W., \& Srivastava, R. (2009). An Analytical Model for External Auditor Evaluation of the Internal Audit Function Using Belief Functions. Contemporary Accounting Research, 27(2), 537-575. http://dx.doi.org/10.1111/j.1911-3846.2010.01016.x

Haat, M. H., Rahman, R. A., \& Mahenthiran, S. (2008). Corporate Governance, Transparency and Performance of Malaysian Companies. Managerial Auditing Journal, 23(8), 744-778. http://dx.doi.org/10.1108/02686900810899518

IIA. (2009a). International Standards for the Professional Practice of Internal Auditing, The Institute of Internal Auditors.

IIA. (2009b). Knowledge Report: Measuring Internal Audit Performance. Retrieved from http://www.theiia.org/GIAN

Krishnamoorthy, G. (2002). A Multistage Approach to External Auditors' Evaluation of the Internal Audit Function. Auditing: A Journal of Practice and Theory, 21(1), 95-121. http://dx.doi.org/10.2308/aud.2002.21.1.95

Mihret, D. G., \& Yismaw, A. W. (2007). Internal audit effectiveness: an Ethiopian public sector case study. Managerial Auditing Journal, 22(5), 470-484. http://dx.doi.org/10.1108/02686900710750757

Mihret, D. G., James, K., \& Mula, J. M. (2010). Antecedents and Organizational Performance Implications of Internal Audit Effectiveness. Pacific Accounting Review, 22(3), 224-252. http://dx.doi.org/10.1108/01140581011091684

Prawitt, D. F., Smith, J. L., \& Wood, D. A. (2009). Internal Audit Quality and Earnings Management. The Accounting Review, 84(4), 1255-1280. http://dx.doi.org/10.2308/accr.2009.84.4.1255

Rupšys, R. (2007). Practical Aspects of the Integration of Internal Audit Activities Measures. Economics \& Management, 108-113.

Rupšys, R., \& Boguslauskas, V. (2007). Measuring Performance of Internal Auditing: Empirical Evidence. Engineering Economics, 9-15.

Ruud, T. F. (2003). Research opportunities in internal auditing, the internal audit function: an integral part of organizational governance. Altamonta Springs, FL, The Institute of Internal auditors.

Saudi Arabian Monetary Agency. (2010). Quarterly Statistical Bulletin.

Schneider, A. (2010). Assessment of Internal Auditing by Audit Committees. Academy of Accounting \& Financial Studies Journal, 14(2), 19-26.

Seminogovas, B., \& Rupšys, R. (2006). Creating Strategy maps for Internal audit activity in the context of BSC. Management of Organizations: Systematic Research, 39, 215-227. 
Spira, L. F., \& Page, M. (2003). Risk Management: The Reinvention of Internal Control and the Changing Role of Internal Audit. Accounting, Auditing and Accountability Journal, 16(4), 640-61. http://dx.doi.org/10.1108/09513570310492335

TADAWUL. (2013). Saudi Stock Exchange Website. Retrieved from http://www.tadawul.com.sa

Vondra, A., \& Schueler, D. (1993). Can you Innovate your Audit. Financial Executive, 9(2), 34-39.

World Economic Forum. (2013). The Global Competitiveness Report (2012-2013). Retrieved from http://www3.weforum.org/docs/WEF_GlobalCompetitivenessReport_2012-13.pdf

Yee, C. S., Sujan, A., James, K., \& Leung, J. K. S. (2008). The Perception of the Singaporean Internal Audit Customers Regarding the Role and Effectiveness of Internal Audit. Asian Journal of Business and Accounting, 1(2), 147-174.

Zain, M. M., Subramaniam, N., \& Stewart, J. (2006). Internal Auditors' Assessment of their Contribution to Financial Statement Audits: The Relation with Audit Committee and Internal Audit Function Characteristics. International Journal of Auditing, 10(1), 1-18. http://dx.doi.org/10.1111/j.1099-1123.2006.00306.x

\section{Copyrights}

Copyright for this article is retained by the author(s), with first publication rights granted to the journal.

This is an open-access article distributed under the terms and conditions of the Creative Commons Attribution license (http://creativecommons.org/licenses/by/3.0/). 